\title{
JUST IN SEQUENCE DELIVERY IMPROVEMENT BASED ON FLEXSIM SIMULATION EXPERIMENT
}

\author{
Pawel Pawlewski \\ Karolina Rejmicz \\ Kamil Stasiak \\ Michał Pieprz \\ Poznan University of Technology \\ Ul.Strelecka 11, Poznań POLAND
}

\begin{abstract}
Nowadays, automotive industry is focused at satisfying at maximum individual demands of the consumers. It is related with a wide range of offered products, which becomes a challenge for logistics. Limited space around an assembly line, necessity for assuring continuity of production, high costs of storing stock and storage space force people to use JIS delivery. This kind of delivery is a complex process, which depends on many factors such as tact time, quantity of parts in transport container, etc. It opens possibilities for using different kinds of technology, e.g. computer simulation. Present paper shows the example application of simulation in logistics process. The main problem to solve was the quantity of containers in sequencing delivery process of car windows. Article presents the problem definition, structure of build model, tool construction and some of the experiments which were made on the simulation model.
\end{abstract}

\section{INTRODUCTION}

The complexity of cars nowadays calls for a great number of diverse components used in the process of production. The Motor \& Equipment Manufacturers Association (MEMA) estimates this number to be about 3,800 components. Given the fact that some components may have to be used more than once in a single car, their total number rises up to about 35,000 . Such complexity and the general tendency to reduce time and cost of delivery has encouraged the Original Equipment Manufacturers (OEMs) to seek different procedures in order to improve the designing, preparation and production processes of on the global scale. The main goal of OEMs is to provide an offer that would base on the correlation between the product and the consumer's preferences by developing "build-to-order" products (Holweg and Pil 2004) which provide a wide range of options to be selected by customers. Although such service is appreciated by clients, it considerably raises the degree of the process complexity and, statistically, only 2 out of 500,000 cars are identical (Graf 2006). Consequently, there may be massive product complaints due to erroneously assembled vehicles and this problem may concern even the best OEM's, such as Toyota. To face such problems, OEMs have to develop highly efficient manufacturing processes. It can be well epitomized by the North American division of Toyota, where labor per vehicle (including assembly, stamping and power train operations) goes up to 30.4 hours per vehicle (Harbour Report 2008); Toyota's factories also make use of $100 \%$ assembly capacity. Such effectiveness is possible by efficient control of the complex supply chain system which is partly based on the Just-In-Time delivery synchronized with the JustIn-Sequence production.

The paper discusses issues related to the effective production sequencing. Planned production sequence implementation may encounter a variety of disruptions that may lead to its disintegration, and then affects not only quality of vehicles produces, but also creates disruptions across the supply chain (Bagdia 


\section{Pawlewski, Rejmicz, Stasiak, and Pieprz}

Pasek 2005). Such an issue requires that OEMs develop strategies effectively coordinating both the flow of the production process and the flow of necessary supplies in such a way as to minimize potential detrimental de-synchronization effects.

The main goal has been to create a tool, which will to make operational decisions in Car Manufacturer. The simulation model should enable controlling the actual sequencing delivery system and testing the influence of each parameter at the process.

The second section contains the description of the current conditions that automotive industry plants work in as far as supply chains are concerned. In this section also the factors of manufacturing process and delivery methods used in the OEM which are realized in the supply chain in question are analysed. Detailed description of the JIS delivery in the plant of automobile industry is presented. The third section defines the problem, describes boundary conditions and presents the description of the general analytical methods used nowadays. The next section proposes a solution to the problem, describes the simulation experiment, and provides the report. The last section constitutes a final conclusion on the simulation tools in the solution of the defined problem.

\section{MANUFACTURING PROCESS IN SUPPLY CHAIN}

The manufacturing can be described as a subsystem of a company, which is responsible for the management of materials, people and processes in order to reach required quality of products in desirable time and by pre-determined cost level. To fulfill this goal many delivery processes are necessary. These processes constitute the supply chain.

Taking into consideration the wide range of tasks in diverse areas, it is more and more common for automotive industry enterprises to make use of logistics providers. Their main aims consist of such actions as comprehensive delivery operations, stock-keeping and delivered commodity sequencing. It is the aim of the logistics provider to organize and carry out those action in the best possible manner, e.g. using the Just-In-Time and Just-In-Sequence delivery, with simultaneous attempts to limit costs of the plant and of the logistics provider itself. To assure the reliable character of its services, logistics providers make use of computer systems such as Track\&Trace in order to follow the delivery on the way. They also focus only on the value added logistics type of tasks. This type of co-operation allows automotive plants to avoid unnecessary additional actions and to fulfill core business tasks more efficiently. One of the most commonly used delivery methods are the JIT and JIS types whose aim is to synchronize the moment of delivery with the moment of the assembly, to minimize storage by frequent deliveries of small portions and to eliminate defects. Using the JIT and JIS is only feasible with a close integration in the supply chain because the execution of these types of delivery is interwoven with a fast and constant flow of information. As a result of this kind of co-operation, safety buffers may be eliminated, delivery operation time shortened and the storage and quality indices improved.

The manufacturing system is treated as a complex entity combining technological, social, and economic subsystems, affected by business environment. Production planning in dynamically changing business environment must be capable of dealing with uncertainty, enable fulfillment of customer's expectations with shorter delivery times, higher quality, and cost effectiveness, as it determines the company's competitive position. Production planning based on the Planned Order Release schedule and MRP concept seems to help to meet aforementioned requirements. Comprehensive literature on a variety of buffering or dampening techniques to minimize the effect of uncertainty can be found in (Guide and Shiverasta 2000). The underlying causes of uncertainty and effects they have on the manufacturing planning system with MRP have been described in (Koh and Saad 2003), (Koh, Saad, and Jones 2002), who evaluated model for diagnosis of manufacturing planning activities in order to identified why problems with late deliveries of finished product appeared.

In the case of automotive industry where Just-in-Time deliveries are common, business practice changes that appear in Master Production Schedule (MPS) result in deteriorating on-time customer order fulfillment. A lot of research conducted in automotive industry regarding the performance improvement concentrated mainly on material flow management within supply chain and integration of planning activi- 
ties (Childerhouse and Towill 2001), (Mason-Jones and Towill 1998), (Towill, Childerhouse, and Disney 2002), (Towill 1999). There is a research gap regarding evaluation of the impact that the disturbances in execution of MPS might have on operational performance.

In the European automobile industry, the initial forecast of customer demand (both in terms of volumes and product specifications) is developed many months ahead of actual production in order to define an attractive product mix for assembly plant balancing. The customer orders that are actually received, are either fitted into the already laid out production plan programmed ahead of time, or the forecast orders in the system are amended to customer requirements - to the extent allowed by the production flexibility. The analyzed production system is typical in today's European automotive industry, and combines traditional mass production features in pre-treatment department with lean production concept in the area of final assembly (Towill 1997).

The desired characteristics of a production system is its high stability defined as (Golinska, Fetrsch, and Pawlewski 2008): steady production plans, high similarity of production routines, and high similarity of product structure (Bill of Materials, or BOM). In order to protect the stability of a production system and achieve the gains of economy of scale, the manufacturer has to combine two policies in production planning: build-to-order and build-to-forecast.

Manufacturing is a sub-process of Customer Ordering Process which, in turn, is a part of Logistical Business Process (Graf 2006) (see Figure 1). Product development process and production planning carried out by Development, and material procurement process executed by Suppliers complete logistical business process model.

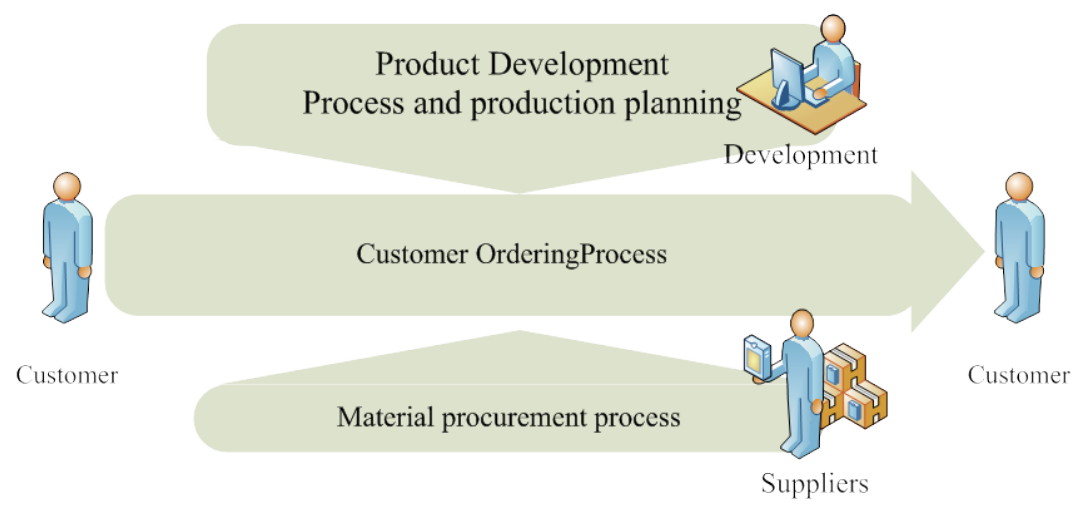

Figure 1: Logistical business process model of a vehicle manufacturer

Customer ordering process, and its relation to material procurement process are shown in Figure 2.

In an automotive factory, where initial testing has been performed, the production sequence is recorded at a number of Production Control Points (see Table 1), that are located within an assembly plant (Figure 3). The desired in-line sequence quality (defined as a combination of sequence quality and deadline quality) is established using special IT-based simulation program. 


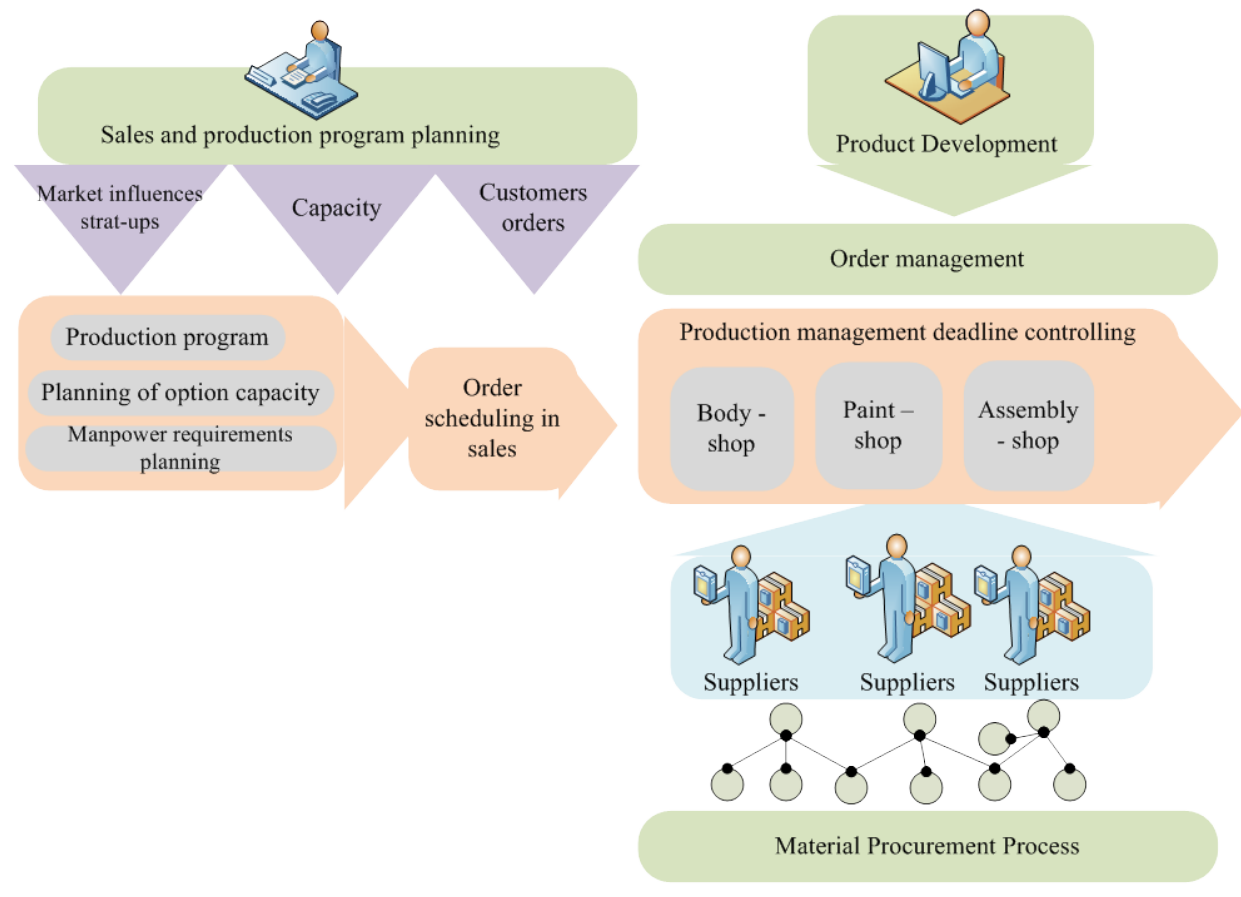

Figure 2: Customer ordering process

Table 1: List of Production Control Points

\begin{tabular}{|l|l|l|}
\hline Nr & status & Description \\
\hline 1 & A & Customer Order Placement \\
\hline 2 & B & Production Order Dispatch \\
\hline 3 & C & Components Request to Parts Warehouse \\
\hline 4 & D & Assembly Kit Matched in Parts Warehouse \\
\hline 5 & E & Assembly Kite Exit from Parts Warehouse \\
\hline 6 & F & Welding of Body-In-White \\
\hline 7 & G & Complete Chassis Assemby \\
\hline 8 & H & Transportation to Painting Department \\
\hline 9 & I & Entry to Painting Dept. - Initial Processing \\
\hline 10 & J & Entry to Sealers \\
\hline 11 & K & Entry to Color Sorter \\
\hline 12 & L & Entry to Polish Line \\
\hline 13 & M & Exit from Polish to Washing Line \\
\hline 14 & N & Entry to Paint Position \\
\hline 15 & O & Decision Point \\
\hline 16 & P & End - Chassis Deposited in Pre-Assembly Buffer \\
\hline 17 & R & Entry to assembly Dept. - Info for Suppliers \\
\hline 18 & Q & Entry to Assembly Dept. - Issuance of Vehicle Control Record \\
\hline 19 & S & End of Assembly \\
\hline 20 & T & Vehicle Testing \\
\hline 21 & U & Corrections \\
\hline 22 & V & End Process - Vehicle Completed \\
\hline
\end{tabular}




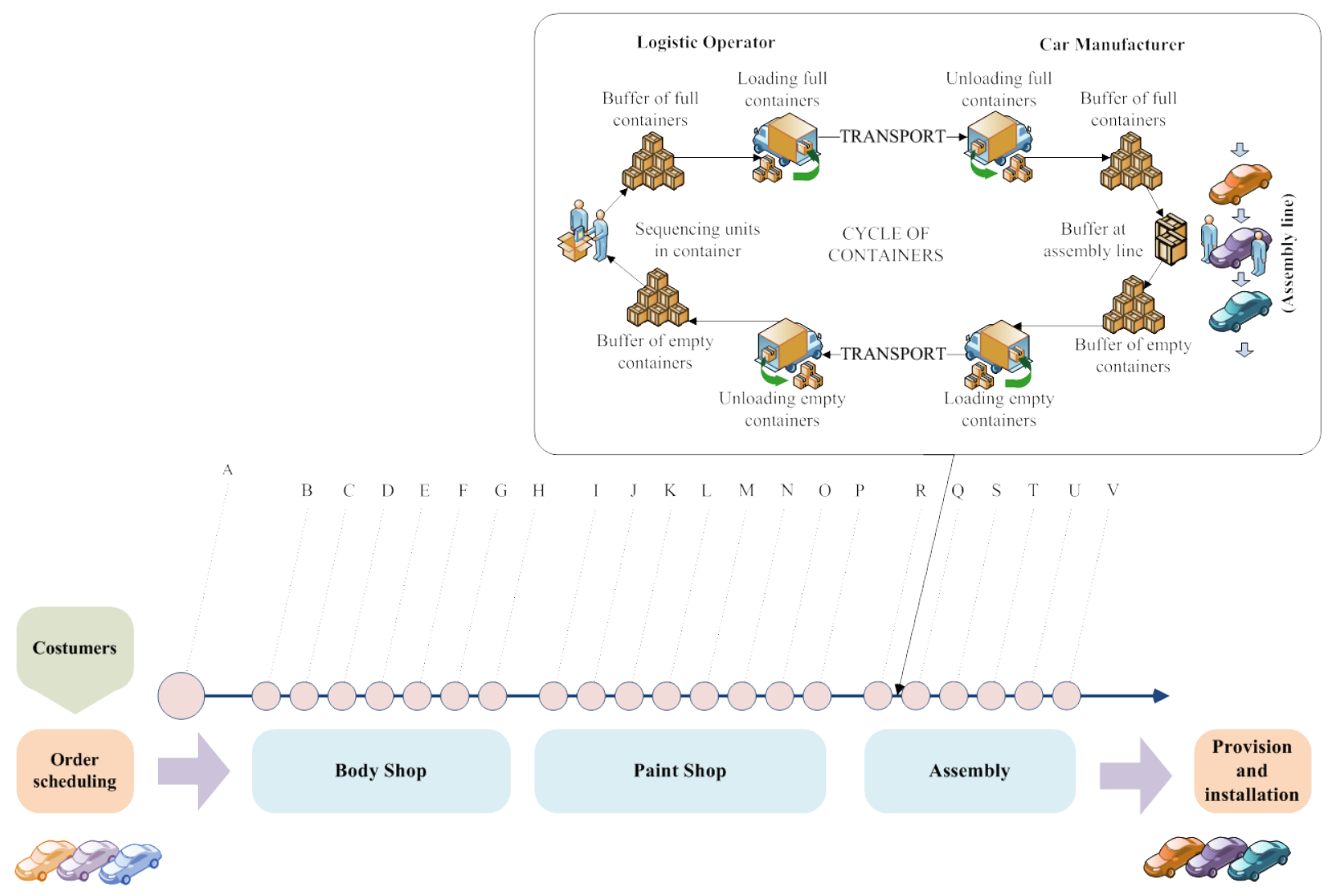

Figure 3: Manufacturing process with Production Control Points and supply chain subprocess

The in-line sequencing enables one of three standard delivery forms: Just-In-Time, Just-In-Sequence and Single-stage inventory chain (Graf 2006), (Islei and Cuthbertson 2006). Presented considerations follow the Just-In-Sequence standard. JIS - Just-In-Sequence is a warehouse-free process, characterized by the delivery of parts, modules, and systems in line with assembly sequences of original equipment manufacturer-OEM (Figure 4). The OEM sends the precise order sequence to the suppliers. For such an arrangement to be effective, the sub-processes (parts and components deliveries) have to be coordinated with the final assembly shop in an optimal manner.

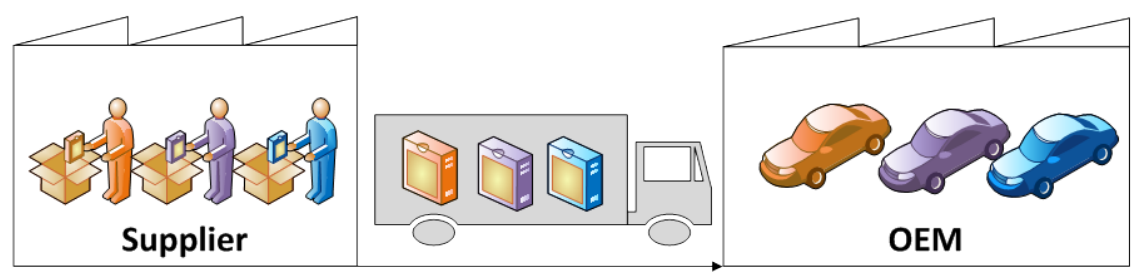

Figure 4: Just-In-Sequence deliveries 


\section{PROBLEM DEFINITION}

The said Car Manufacturer is a modern, independent automobile factory. In the first of its three industrial plants there are located: the body shop, paint shop and assembly department, in the second there is a foundry. In the third plant there takes place the production of welding components and assembly of the cockpits, there is also located the branch of specials cabinetry.

Discussed example relates to the sequential supply of windscreens of two cars manufactured in this Car Manufacturer. Windscreens belong to the 100\%-parts, which means that they are part of all manufactured models and types of cars. They are supplied in sequence in special containers, which help to arrange the windscreens in the order in which they are later used in the assembly line. The capacity of the said container is 12 items at maximum (regardless of car model).

The cycle of the containers (Figure 3 - part "Cycle of Containers") starts from the buffer of empty containers in a warehouse of Logistics Operator. Every 20 minutes (if only one container has been taken) or every 40 minutes (if two containers have been taken), they are taken in place of the sequencing. Completed containers are transported to the buffer of full containers in the warehouse of Logistics Operator, which is located close to the buffer of empty containers. Workers transport always only one full container to the buffer (due to its weight). The prepared containers are waiting for transport to the Car Manufacturer (1st plant). Tracks that provide containers run regularly on the scheduled basis (approximately every 40 minutes). On the way back they take empty containers. For the transport of containers of the said type, three trucks of Logistics Operator are used and they also carry other parts containers.

The distance between the plants is about 6 kilometers. Full containers go to the appropriate buffer in the Car Manufacturer, from which in the expected time they are delivered to the assembly line by an employee of the Logistics Operator. There should always be two containers by the assembly line, one empty and the other pending. Mostly, however, there are three containers. Tact time of the assembly line rises the time of consumption of items to about 22.2 minutes (tact time multiplied by a number of windscreens in one container). Empty container is taken away from the buffer of the empty containers to the loading platform and is expected to return to Logistics Operator, where the cycle starts over again.

At the beginning of studies, the Car Manufacturer used MS Excel file to find quantity of necessary containers. At this file, the user decides if particular part is for cars type A and B, only type A or only type B. Next, he fills in an appropriate column with all the necessary fields, such as tact time, transport time, sequencing time, quantity of elements in container, etc. After filling in all the fields, the sheet calculates (by the company rules) and shows up the result in an appropriate field. This is a static way of solving the problem and it has a lot of inconveniences. It does not provide the exact number of needed containers in the process. Thereby, there are too many containers in the process.

\section{SIMULATION EXPERIMENT USING FLEXSIM}

A suggested solution to the problem of the quantity of containers is simulation. In this case, the simulation model has been created. This model is supposed to answer the question: how many containers in the process is necessary to keep assembly line working. Moreover, the simulation model should to let take a studies at process, checking influence of particular parameters in whole process. For example - checking how increase of containers quantity or changes in departure of trucks schedule will influence the whole process.

Flexsim Simulation Software has been chosen to solve this problem. Flexsim is new generation simulation software where models are built directly in 3D. It is a modern object oriented, complex analytical tool. The decision to choose this particular tool has been based, among other things, on its user-friendly features, open architecture, easy concept of modeling and full scalability. Also possibilities of presentation, animation and introducing changes directly in 3D have been of crucial importance (Beaverstock, Greenwood, Lavery, and Nordgren 2011). 


\subsection{Simulation Model}

The simulation model is divided into three parts (Figure 5). The first (left) shows the flow of containers in warehouse of Logistics Operator, the second (middle) represents a route between the Logistics Operator and the Car Manufacturer, and the last (right side) displays the flow of containers within the Car Manufacturer. In the main window of the simulation all the key elements and parameters have been placed. Tracking each of the containers is possible in real time. Color of the container also provides information whether it is filled or empty. Each of the buffer presented in the process has been clearly marked to facilitate the observation of the places of potential accumulation of the containers. At the bottom of the main window are placed information about: the nearest truck departure; departure time, taking into account the delay specified in the parameters; the number of boxes in place of sequencing (Logistics Operator) and the number of containers on an assembly line; the maximum number of containers on an assembly line and the next departure of the truck (to Car Manufacturer). In the central part of the window an information about the current date and time of the simulation and the counter functioning containers in circulation are placed. A number indicating the quantity of parts that are currently in the used container is shown in the fields of assembly and completion. The introduction of containers in the model follows directly from the "virtual buffer". This is a fictional buffer, whose capacity is equal to the maximum number of containers in circulation imputed with a proper parameter. Containers available at the "waiting room" are gradually introduced into the model so as to ensure continuity of supply. During the running of the model, the introduction of containers may be carried out in one of three ways - through the assembly station; by sequence stand, or in a hybrid way. The introduction of containers through the assembly process gives it a higher priority than the process of sequencing, it is a normal situation. Upon starting-up the model the production line is also running. The line charges ("pull") from the virtual buffer the container required to perform an installation. At this time the sequencing doesn't take place. The assembly position gradually gets more virtual containers from the buffer. During this time, the first empty containers go to the place of sequencing, where they are filled. After some time the model is balanced, assembly line no longer gets new virtual containers from the buffer because it is fully supplied from sequencing. This is the optimal start-up model. If the available pool of virtual containers in the buffer is used, but the line at the right time does not get a full container, a warning about missing containers on the assembly line will be shown. The introduction of containers through the process of sequencing gives it a higher priority than in the assembly process. At the time of starting-up the model a container is taken to the sequencing place from the virtual buffer. At that time, assembly line is not used. The assembly begins when first filled containers come to the line. After some time the model is balanced, sequencing process no longer takes new containers from the virtual buffer. This mode is not possible if the option responsible for stopping the simulation is enabled. The introduction of containers in a hybrid way relies on simultaneous charging of containers from a virtual buffer for the sequencing and assembly process. This method enables the fastest start-up of the model. Trucks circuit is independent of the number of prepared containers. Transport will always start on schedule, even if there are no containers prepared. Trucks carrying the containers are marked symbolically on the model. The sections shown in the middle of the window represent the path between the Car Manufacturer and Logistics Operator. Thanks to trucks we can keep track of the actual position of the transport. The reading of the control MS Excel file occurs only during the booting of the model. All data required for the functioning is then loaded by the program and saved under the appropriate variables. Information about following shipments are exported during simulation to an external MS Excel spreadsheet. For each of them, there is the information on departure times from different positions and the number of containers being taken each time. 


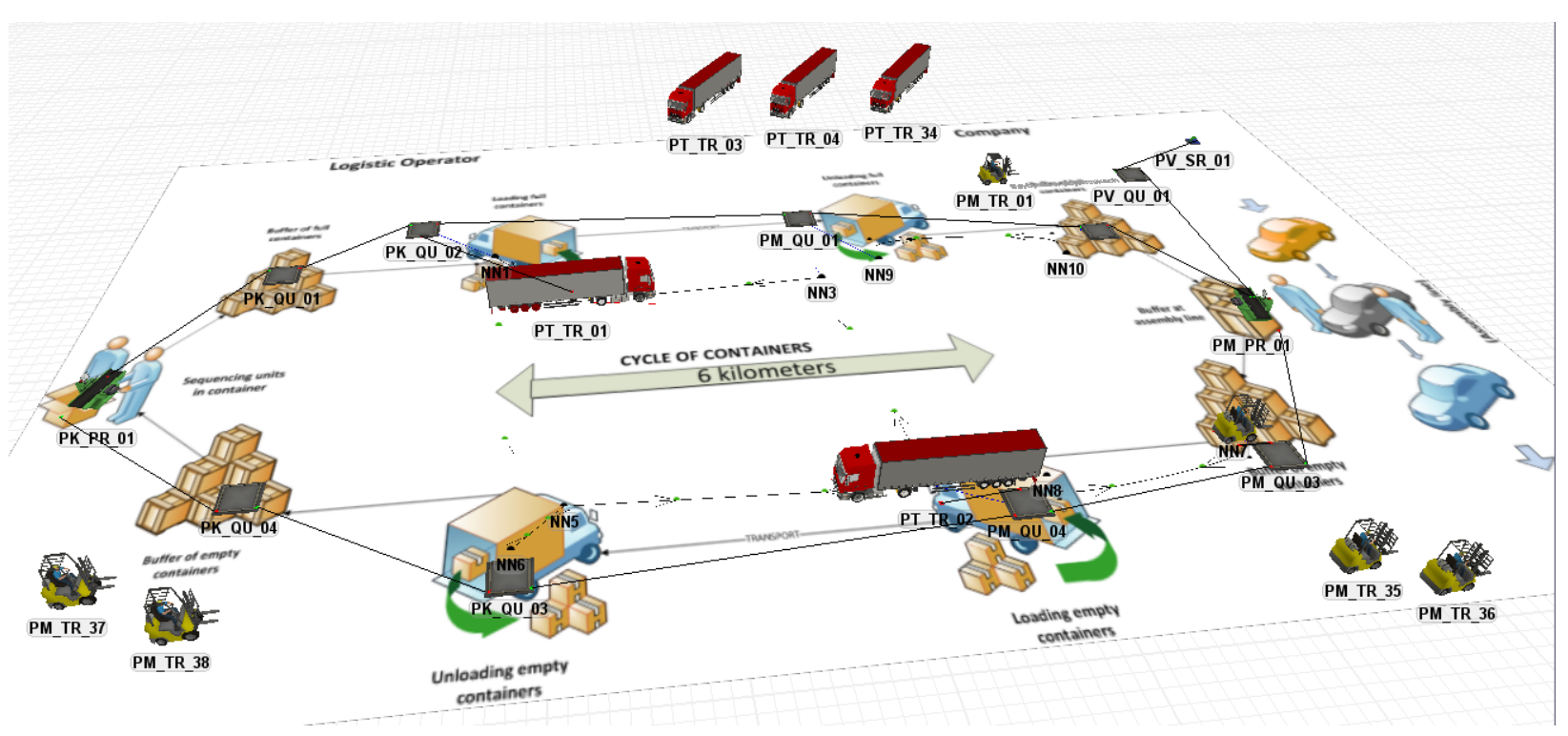

Figure 5: Simulation model 3D of delivery process in Flexsim - fragment

\subsection{Tool Construction}

The simulation model has been connected to MS Excel files. Thanks to that, the control and modification of each parameter is easier, because user does not have to change the whole model but only a particular field. The simulation model uses two files:

- control.xlsx (contains sheets: SCHEDULE, BREAKS, TIMES, SUMMARY AND MEASUREMENTS)

- measurements.xlsx (contains sheet: TRANSPORT).

First file is an input file to start simulation. All the necessary data is taken from control.xlsx. Using it, user can change almost all parameters, variables and times, which directly affect process. Second file is an output file. Selected data are saved in measurements.xlsx

Sheet SCHEDULE - contains truck schedule from Logistics Operator Y. Times of departures must be put in chronological order in an appropriate column. Standard times of departures are located in the next column, so it is easy to restore the initial schedule. For a better image of a real situation, in this sheet there's a possibility to add deviation of departure time. This option can be active with drop-down list "Deviation".

Sheet BREAKS - contains timetable of breaks in Car Manufacturer and at Logistics Operator Y. Time of breaks must be put in chronological order. For both companies there is a possibility to define 8 breaks. This sheet has been set with actual times of breaks in both companies. There is a possibility to turn off this parameter in the sheet PARAMETERS.

Sheet PARAMETERS - enables the setting and changing the most important parameters, which affect process. All of the parameters are grouped in six tables: primary parameters, loading parameters - Logistics Operator Y, loading parameters - Car Manufacturer, buffer parameters and export data. Most of them are set with drop - down lists.

PRIMARY PARAMETERS

- Tact line $(1,85)$ : specify time of tact production line (minutes);

- quantity in container (12): specify quantity of units (car windows), which can be loaded in one container;

- maximum containers in cycle (20): specify maximum quantity of containers, which can be put into the cycle; 
- $\quad$ set containers through ("assembly", alternative option: "complement", "assembly and complement"): specify place of setting containers into cycle during the starting of the simulation model;

- stop simulation when there is a lack of containers at assembly line (,yes", alternative option: „no"): when it is on, it stops the simulation and displays proper statement in case there is no more containers at assembly line;

- include breaks at work (,yes”, alternative option: „no”): turns on or turns off the use of breaks at work (described at sheet BREAKS).

LOADING PARAMETERS - LOGISTICS OPERATOR

- start (min before departure) (20): specify how long before the planning departure (sheet SCHEDULE) workers should start to load the truck;

- end (min before departure) (5): specify how long before the planning departure (sheet SCHEDULE) workers should finish loading the truck. All containers which come to the buffer should not be taken after this time (this time is needed for security transport).

LOADING PARAMETERS - CAR MANUFACTURER

- $\quad$ start (min after unloading) (0): specify how long after the unloading of full containers workers should start to load the empty containers ;

- end (min before departure) (5): specify how long before the planning departure workers should finish loading the truck. All containers which come to the buffer should not be taken after that time (this time is needed for security transport).

BUFFER PARAMETERS

- maximum number of containers, which can be taken to the sequencing at one time. (2)

- minimum number of containers, which can be taken to the sequencing place at on time . (1)

- Determine how many containers can be transported to the sequencing place at one time, at the Logistics Operator Y.

- maximum number of containers, which can be taken to the assembly place at one time (2)

- minimum number of containers, which can be taken to the assembly place at one time (1)

- Determine how many containers can be transported to the assembly line at one time, at Car Manufacturer.

- maximum number of containers, which can be taken from assembly place at one time (2)

- minimum number of containers, which can be taken from assembly place at one time (1)

- Determine how many containers can be transported from the assembly line to the buffer with empty containers at one time, at Car Manufacturer.

- $\quad$ maximum take full (Logistics Operator - Car Manufacturer) (3)

- maximum take empty (Car Manufacturer - Logistics Operator) (3)

- Determine how many containers can be transported between Car Manufacturer and Logistics Operator at one time.

- buffer capacity at assembly line (3): specify maximum quantity of containers, which can stay at assembly line.

INITIAL STATE OF BUFFERS

- buffer with empty containers (Logistics Operator) (2)

- buffer with full containers (Logistics Operator) (2)

- buffer with empty containers Car Manufacturer (2)

- buffer with full containers Car Manufacturer (2)

- Determine the quantity of every buffer at the start of the simulation. It allows a faster starting simulation model.

- The last table "export data" contains only one option " truck cycle". It provides the observation data, which are received from the running simulation. The results are shown at a separate MS Excel file (measurements.xlsx). 
Sheet TIMES - enable setting times for every subprocess. This sheet allows to set constant and variable parameters, which are described by one of five random distributions. An appropriate distribution is set with drop - down list (distributions: normal, exponential, logarithmic, triangle, uniform). Depending on a chosen distribution, the user needs to fill in some fields with proper data.

Sheet MEASUREMENT - it is a summary of measurement for every subprocess, which are gained during the survey in the companies. All measurements are collected in the table.

Sheet SUMMARY - All times are collected in the table and set in form, which allows to export them to the simulation program. The user can't edit this sheet.

\subsection{Experiments}

The created simulation model allows to perform the simulation of sequencing delivery process for car windows. All times and parameters have been set to a standard value (value of parameters and times have been taken from the survey). Next step has been to perform simulation for 30 days of work. The goal of performed simulation has been to define minimum number of containers in the cycle (which are needed to keep the continuity of assembly line work).

For standard parameters, 11 containers are enough to keep assembly line working. It means that the Car Manufacturer has almost twice as many containers as they need. Reducing quantity of containers can result in considerable savings.

Next step bas been to perform another simulations with different parameters. It has been the quantity of windows in a container and time of sequencing that have been changed in additional simulations .

All the simulations were performed for 30 working days. Moreover, all initial states of buffers have been set to zero (sheet PARAMETERS), table "initial state of buffers". Containers have been set via the assembly.

Results of all performed simulations are shown in table below (Table 2).

First three lines contain time of sequencing one container. Triangle division has been used, so minimum, maximum and dominant time has been taken into consideration. Next, the fourth line contains quantity of windows in a container. Next two lines include the percentage of quantity of a unit in containers in proportion to standard value. Next line contains trucks departures (from sheet SCHEDULE). The last line " quantity of containers" contains the minimum quantity of containers needed to keep the continuity of assembly line work (depends on exact parameters). Green color means that the number of containers is lower than with standard parameters.

Table 2: Summary of simulation tests

\begin{tabular}{|l|l|l|l|l|l|l|l|l|}
\hline \multicolumn{2}{|l|}{ Example (number) } & St. & $\mathbf{1}$ & $\mathbf{2}$ & $\mathbf{3}$ & $\mathbf{4}$ & $\mathbf{5}$ & $\mathbf{6}$ \\
\hline \multirow{2}{*}{$\begin{array}{l}\text { Time of sequencing } \\
\text { one container }\end{array}$} & Min & 15 & 19 & 23 & 30 & 12 & 8 & 15 \\
\cline { 2 - 9 } & $\mathrm{D}$ & 17 & 20 & 26 & 34 & 13 & 9 & 17 \\
\cline { 2 - 9 } & Max & 20 & 25 & 30 & 40 & 15 & 10 & 20 \\
\hline Quantity of units in container & 12 & 15 & 18 & 24 & 9 & 6 & 12 \\
\hline $\begin{array}{l}\text { Percentage change quantity of } \\
\text { units in container }\end{array}$ & $0 \%$ & $25 \%$ & $50 \%$ & $100 \%$ & $-25 \%$ & $-50 \%$ & $0 \%$ \\
\hline $\begin{array}{l}\text { Percentage change quantity of } \\
\text { containers }\end{array}$ & $0 \%$ & $-18 \%$ & $-27 \%$ & $-36 \%$ & $18 \%$ & $55 \%$ & \\
\hline Truck timetable (every ... min) & 40 & 40 & 40 & 40 & 40 & 40 & 30 \\
\hline Quantity of containers & 11 & 9 & 8 & 7 & 13 & 17 & 10 \\
\hline
\end{tabular}

There's a possibility that changing some parameters leads to savings but to make a decision, the Car Manufacturer needs to make a financial analysis. 


\section{Pawlewski, Rejmicz, Stasiak, and Pieprz}

In all of this tests it has been assumed that the time of sequencing of one container changes linearly depending on the quantity of units in the container. In reality, the linearity does not have to be true, so this parameter could be different. It also can have an impact on the final quantity of containers.

\section{CONCLUSIONS}

The main goal during the creation of this simulation model has been to build a tool, which will help to make operational decisions in the Car Manufacturer. The created simulation model enables controlling the actual sequencing delivery system. The model also makes it possible to test the influence of each parameter on the process. It also offers the possibility of the development of universalization.

Thanks to using the simulation program, it has been possible to run tests and studies at this particular process. Moreover, thanks to Flexsim software the visualization of the process has been possible. The visualization permits the better understanding of the relationships in the process.

To make the model more flexible, it has been connected with the MS Excel file. On this account, it has been possible to change every parameter. Each change has an influence on the model operation, so it is easy to watch and study how process operates in different situations.

The created model for cars windows is very elastic and gives the possibility improvement and development. There is also the possibility to enclose other sequencing deliveries, which are carried out in the Car Manufacturer.

\section{REFERENCES}

Bagdia, R. and Pasek, Z. J. 2005. "Upstream Demand Projection and Performance Mapping in Supply Chains." In Proceedings of the 2005 Winter Simulation Conference, Edited by M.E.Kuhl, N.M.Steiger, F.B.Armstrong, J.A. Joines, Piscataway, New Jersey: Institute of Electrical and Electronics Engineers, Inc.

Beaverstock M., Greenwood A., Lavery E., and Nordgren W. 2011. Applied Simulation, Modeling and Analysis usinf Flexsim, Flexsim Software Products, Inc. Orem, USA

Childerhouse, P. and Towill, D.R. 2001. "Simplified Material Flow Holds the Key to Supply Chain Integration". The International Journal of Management Science, OMEGA, no. 31, pp. 17-27.

Golińska P., Fertsh M. and Pawlewski P. 2008. "Improvement of production flow control in a machines' assembly plant in conditions of delivery and process lead times uncertainty." Proceedings Flexible Automation and Intelligent Manufacturing, FAIM2008, Skövde, Sweden 30.06-2.07.2008

Graf H., 2006. "Innovative logistics is a Vital part of Transformable Factories in the Automotive industry", In Reconfigurable manufacturing systems and transformable factories. Springer pp.423-457

Guide V.D.R. and Shiverasta R., 2000. "A review of techniques for buffering against uncertainty with MRP systems, production." Planning and Control vol. 11, pp.223-233.

Harbour Report. 2008. http://www.oliverwyman.com/ow/automotive.htm, viewed on Feb. 11, 2009

Holweg, M. and Pil, F. K. 2004. The Second Century. Reconnecting Customer and Value Chain through Build-To-Order, MIT Press, Cambridge, MA9.

Islei G. and Cuthbertson R. 2006. "Measuring performance in Supply Chains", Proceedings of LSCM2006, Hong Kong, 5-7.01.2006.

Koh L.S.C. and Saad S.M. 2003. "How Uncertainty Disturbs SME Manufacturers." Proceeding of 17th $I C P R$, Blacksburg, Virginia, USA.

Koh L.SC., Saad S.M and Jones. 2002. "Uncertainty under MRP-planned manufacture: review and categorisation." Journal of Production Research vol.31, pp. 2399-2421.

Mason-Jones, R. and Towill, D.R. 1998. "Shrinking the Supply Chain Uncertainty Circle." Control, The Journal of the Institute of Operations Management, vol. 24 no. 7, pp. 17-22.

Towill, D.R., Childerhouse P. and Disney S.M. 2002. "Integrating the Automotive Supply Chain: Where are we Now?" International Journal of Physical Distribution and Logistics Management, vol. 32, no. 2, pp. 79-95. 
Towill, D.R. 1999. "Simplicity Wins: twelve rules for designing effective supply chains." Control, the Journal of the Institute of Operations Management, vol. 25, no. 2, , pp. 9-13.

Towill, D.R. 1997. “The Seamless Supply Chain”, International Journal of Technology Management, vol. 13 , no. 1 , pp. $37-56$

\section{AUTHOR BIOGRAPHIES}

PAWEL PAWLEWSKI works as an Assistant Professor at the Department of Computing and Management, Poznan University of Technology. He holds a PhD in Mechanical Engineering, specialization "organization of production systems" from the Poznan University of Technology. His research interests include organization of manufacturing systems, monitoring of operations management, reengineering and IT application for logistics. He is managing director of SOCILAPP Simulation and Optimization Center in Logistics and Production Processes. His e-mail address is pawel.pawlewski@put.poznan.pl.

KAROLINA REJMICZ is an engineer. She received a diploma in Logistics from the Poznań University of Technology. Since 2011 she has been taking part in Engineer Development Programme by Volkswagen Poznań. She works as an intern in Logistic Planning Department. Hers email address is karolina.rejmicz@gmail.com.

MICHAL PIEPRZ is an engineer. He received a diploma in Logistics from the Poznań University of Technology. Since 2011 he has been taking part in Engineer Development Programme by Volkswagen Poznań. He works as an intern in Disposition Department. His email address is michal.pieprz@gmail.com.

KAMIL STASIAK is an engineer. He received a diploma in Logistics from the Poznan University of Technology. Since 2011 he has been taking part in Engineer Development Programme by Volkswagen Poznań. He works as an intern in Assembly Department. His email address is kamil.stasiak89@gmail.com. 